\title{
Secreted phospholipase A2 of Clonorchis sinensis activates hepatic stellate cells through a pathway involving JNK signalling
}

Yinjuan Wu ${ }^{1,2,3}$, Ye Li ${ }^{1,2,3}$, Mei Shang ${ }^{1,2,3}$, Yu Jian ${ }^{1,2,3}$, Caiqin Wang ${ }^{1,2,3}$, Adham Sameer A. Bardeesi $i^{1,2,3}$, Zhaolei Li ${ }^{1,2,3}$,

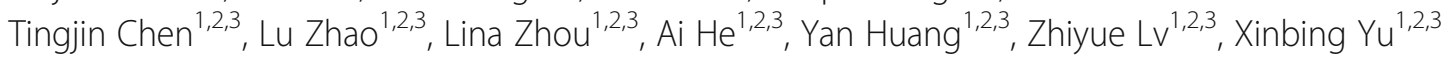
and Xuerong $\mathrm{Li}^{1,2,3^{*}}$

\begin{abstract}
Background: Secreted phospholipase A2 (SPLA2) is a protein secreted by Clonorchis sinensis and is a component of excretory and secretory products (CSESPs). Phospholipase A2 is well known for its role in liver fibrosis and inhibition of tumour cells. The JNK signalling pathway is involved in hepatic stellate cells (HSCs) activation. Blocking JNK activity with SP600125 inhibits HSCs activation. In a previous study, the protein CsSPLA2 was expressed in insoluble inclusion bodies. Therefore, it's necessary to express CsSPLA2 in water-soluble form and determine whether the enzymatic activity of CSSPLA2 or cell signalling pathways is involved in liver fibrosis caused by clonorchiasis.

Methods: Balb/C mice were given an abdominal injection of MBP-CsSPLA2. Liver sections with HE and Masson staining were observed to detect accumulation of collagen. Western blot of mouse liver was done to detect the activation of JNK signalling pathway. In vitro, HSCs were incubated with MBP-CSSPLA2 to detect the activation of HSCs as well as the activation of JNK signalling pathway. The mutant of MBP-CSSPLA2 without enzymatic activity was constructed and was also incubated with HSCs to check whether activation of the HSCs was related to the enzymatic activity of MBP-CSSPLA2.
\end{abstract}

Results: The recombinant protein MBP-CssPLA2 was expressed soluble and of good enzymatic activity. A mutant of CssPLA2, without enzymatic activity, was also constructed. In vivo liver sections of Balb/C mice that were given an abdominal injection of $50 \mu \mathrm{g} / \mathrm{ml} \mathrm{MBP-CSsPLA2}$ showed an obvious accumulation of collagen and a clear band of P-JNK1 could be seen by western blot of the liver tissue. In vitro, MBP-CSSPLA2, as well as the mutant, was incubated with HSCs and it was proved that activation of HSCs was related to activation of the JNK signalling pathway instead of the enzymatic activity of MBP-CSSPLA2.

Conclusions: Activation of HSCs by CSSPLA2 is related to the activation of the JNK signalling pathway instead of the enzymatic activity of CsSPLA2. This finding could provide a promising treatment strategy to interrupt the process of liver fibrosis caused by clonorchiasis.

Keywords: Phospholipase A2, Clonorchis sinensis, Enzyme, Liver fibrosis, Cholangiocarcinoma, JNK signalling pathway

\footnotetext{
* Correspondence: xuerong2@mail.sysu.edu.cn

'Department of Parasitology, Zhongshan School of Medicine, Sun Yat-sen University, Guangzhou, Guangdong 510080, People's Republic of China

${ }^{2}$ Key Laboratory of Tropical Disease Control (Sun Yat-sen University), Chinese Ministry of Education, Guangzhou, Guangdong 510080, People's Republic of China

Full list of author information is available at the end of the article
} International License (http://creativecommons.org/licenses/by/4.0/), which permits unrestricted use, distribution, and reproduction in any medium, provided you give appropriate credit to the original author(s) and the source, provide a link to the Creative Commons license, and indicate if changes were made. The Creative Commons Public Domain Dedication waiver (http://creativecommons.org/publicdomain/zero/1.0/) applies to the data made available in this article, unless otherwise stated. 


\section{Background}

Clonorchis sinensis is a parasite prevailing mainly in eastern countries. In China, northern Vietnam and South Korea about 15 million people are infected; 13 million infected people come from China alone [1-4]. In 1975, eggs of $C$. sinensis were found in a corpse of the Western Han Dynasty in Hubei province, which showed that the disease appeared at least two millennia ago [5]. When raw or undercooked infected fish is eaten by people, the metacercaria is excysted by gastric juice from the flesh in the duodenum [6]. Cholangitis, cholecystitis and cholelithiasis are the main complications caused by the chronic infection with C. sinensis [7-9]. Infiltration of eosinophils and mast cells, fibrosis and mucosal hyperplasia of the gallbladder wall are also associated with infection [10]. Infection is widely considered to be related to cholangiocarcinoma (CCA). The morbidity of CCA caused by $C$. sinensis each year is about $0.035 \%$ in males and $0.025 \%$ in females [2].

Clonorchis sinensis excretory/secretory products (CsESPs) is proved to result in liver fibrosis in clonorchiasis. Secreted phospholipase A2 (sPLA2) is a protein secreted by $C$. sinensis and is a component of CsESPs. sPLA2 enzymes, characterised by low-molecular-weight, calcium-dependent and a His-Asp catalytic dyad, refer to the largest family among the phospholipase A2 (PLA2) superfamily [11]. The parasite lives in the bile duct of the liver and is exposed to bile which is rich in fatty acid. CssPLA2, which was proved to be a component of the ESPs of $C$. sinensis, plays an important role in the growth of the parasite by breaking down complex lipids $[12,13]$. Liver fibrosis is observed in patients with moderate or severe infection of liver fluke. Deficiency of Group IVA phospholipase A2 (IVA-PLA2) alleviates the deposition of lipids and delays the formation of liver fibrosis [14]. CssPLA2 of C. sinensis may lead to liver fibrosis and HSCs activation which is related to c-Jun $\mathrm{N}$-terminal kinase (JNK) signalling pathway. When JNK signalling pathway is blocked by inhibitor SP600125, hepatic stellate cells (HSCs) activation is inhibited, with less proliferation and reduced expression of $\alpha$-smooth muscle actin ( $\alpha$-SMA) [15]. An increased expression of collagen III has been detected in LX- 2 cells by quantitative RT-PCR after incubating with the recombinant CssPLA2 which was a renatured protein from inclusion bodies [12]. CssPLA2 was difficult to express in soluble form and only little insoluble inclusion bodies renatured by dilution and dialysis were obtained. Both of cell cycle analysis and MTT test of LX-2 demonstrated that the percentage of cells in the proliferation phase was higher [12]. PLA2 from snake venoms have been widely studied because of the pathophysiological and pharmacological effects including antiangiogenic and antitumor properties on living organisms [16-18].

To detect the activation of hepatic stellate cells LX-2 as well as activation of the JNK signalling pathway by the recombinant protein $\mathrm{MBP}-\mathrm{CssPLA2}$, the recombinant protein MBP-CssPLA2 was expressed in soluble form in E. coli and displayed the phospholipase activity. MBPCssPLA2 could activate hepatic stellate cells which could lead to liver fibrosis. The mechanism of the hepatic stellate cells activation is involved in the activation of JNK signalling pathway instead of the enzymatic activity of the protein, which could provide a promising strategy to interrupt the process of liver fibrosis caused by infection of Clonorchis sinensis.

\section{Methods \\ Cloning, expression, and purification of the recombinant protein MBP-CssPLA2}

Polymerase chain reaction (PCR) was used to amplify CDS but not the signal peptide sequence of CssPLA2 gene (GenBank Accession no. DQ974199). The forward and reverse oligonucleotide primers were: $5^{\prime}$-CTA GTC TAG AAA ACC ACG GTC AAT TTC A-3' and $\overline{5{ }^{\prime}-}$ GGG AAG CTT GCT CAT ACA GTA ATG TAC G-3' with $X b a$ I and Hind III sites to the 5 ends, respectively (underlined). Clonorchis sinensis adult cDNA was used as template. Total RNAs from adult worms were extracted in Trizol reagent (Invitrogen, Carlsbad, USA) Amplicons were cloned into pMAL-c2X (New England Biolabs, Ipswich, USA). The nucleotide sequences of the recombinant plasmid CssPLA2/pMAL-c2X were confirmed by DNA sequencing. The recombinant plasmid CssPLA2/pMAL-c2X was expressed in E. coli BL21 (DE3) in Luria-Bertani medium containing $50 \mu \mathrm{g} / \mathrm{ml}$ ampicillin. The final concentration of $0.3 \mathrm{mM}$ isopropyl-1-thio-galactoside (IPTG) was added to induce expression, and the culture was further incubated at $37^{\circ} \mathrm{C}$ for $4 \mathrm{~h}$. The MBPCssPLA2 fusion protein was purified by amylose resin (New England Biolabs, Ipswich, USA) MBP-CssPLA2 was further purified by anion exchange chromatography with an anion exchange column (HiTrap Q FF).

\section{SDS-PAGE and western blot}

The recombinant protein MBP-CssPLA2 was subjected to SDS-PAGE (12\% polyacrylamide gel) and immobilized onto polyvinylidenedifluoride membrane. The membrane was incubated with the primary antibodies (CssPLA2 monoclonal antibody, 1:3000 dilutions in 1\% BSA-PBS) overnight at $4{ }^{\circ} \mathrm{C}$ after blocking with $5 \%$ skim milk at room temperature for $2 \mathrm{~h}$. Then the membrane was washed and incubated with goat anti-mouse IgG conjugated HRP (1:2000 dilution) (Proteintech, Chicago, USA) at room temperature for $1 \mathrm{~h}$. The results were visualized by chemiluminescence (chemiluminescent HRP substrate, Millipore, Billerica, USA)

\section{Mass spectrometry}

The mass spectrometry identification of the recombinant protein MBP-CssPLA2 was carried out by the Proteomics 
Center, Zhongshan School of Medicine, Sun Yat-sen University.

\section{Enzyme activity assay}

The enzyme activity of CssPLA2 was detected by sPLA2 Assay Kit (Cayman, Ann Arbor, USA). The recombinant protein MBP-CssPLA2 was dialysed against PBS. Bee Venom PLA2 was used as the positive and as a negative control, the MBP protein expressed by empty plasmid pMAL-c2x was used. $10 \mu \mathrm{l}$ DTNB, $10 \mu \mathrm{l}$ sample and $5 \mu \mathrm{l}$ assay buffer were added to sample wells. $10 \mu \mathrm{l}$ DTNB, $10 \mu \mathrm{l}$ Bee Venom PLA2 and $5 \mu \mathrm{l}$ assay buffer were added to positive control wells. Negative control wells contain $10 \mu \mathrm{l}$ of DTNB, $10 \mu \mathrm{l}$ of MBP and $5 \mu \mathrm{l}$ of assay buffer. The reactions were initiated by adding $200 \mu \mathrm{l}$ substrate solution to all the wells. The plate was carefully shaken and read at an absorbance of $414 \mathrm{~nm}$ every 1 min using a microplate spectrophotometer (SpectraMax M5, American Molecular Devices, Sunnyvale, USA).

\section{Western blot of mouse liver tissue to detect the activation of the JNK signalling pathway}

$\mathrm{Balb} / \mathrm{C}$ mice with weights of $18-20 \mathrm{~g}, 6-8$ weeks of age, male and cared for in a SPF environment were divided into five groups with three mice in one group, and were given an abdominal injection of PBS, $100 \mu \mathrm{g}$ ESPs of Clonorchis sinensis, $100 \mu \mathrm{g}$ MBP protein (negative control), $50 \mu \mathrm{g}$ of MBP-CsPLA2 protein and $100 \mu \mathrm{g}$ of MBP-CssPLA2 protein, respectively, twice a week. The mice were sacrificed four weeks later and liver sections with $\mathrm{HE}$ and Masson staining were observed for collagen accumulation. Western blot of the mice liver tissue was also done to detect the activation of the JNK signalling pathway related to liver fibrosis.

\section{Construction of MBP-CssPLA2 mutant without enzymatic activity}

The enzymatic center of PLA2 protein is comprised of two key amino acids, His192 and Asp222. Here, His192 of CssPLA2 was changed into Asn192. Fast mutagenesis system (Transgen Biotech, Beijing, China) was applied to deliver the mutation. PCR amplification was performed with two overlapping primers. Both primers contain the target mutation. The forward and reverse oligonucleotide primers were: $5^{\prime}$ CTG ACA TGT GCT GTC GAA CT A ATG ACC GAT G-3' and 5' -TAG TTC GAC AGC ACA TGT CAG TCT CGA TTT C-3'. PCR was performed under conditions of the $20 \mathrm{~s}$ at $94{ }^{\circ} \mathrm{C}, 20 \mathrm{~s}$ at $57{ }^{\circ} \mathrm{C}$, and 3.5 min at $72{ }^{\circ} \mathrm{C}$ for 25 cycles and recombinant plasmid CssPLA2/pMAL-c2X was used as a template. The difference between the mutant and MBP-CssPLA2 is only one amino acid, therefore the expression and purification of the protein of mutant are the same with that of MBP-
CssPLA2. The enzymatic activity of the mutant is determined by sPLA2 Assay Kit (Cayman, Ann Arbor, USA).

\section{Detection of collagen I in LX-2 cells incubated with MBP- CsSPLA2 by ELISA}

LX-2 cells were cultured in Dulbecco's modified Eagle medium (DMEM, Gibco, Carlsbad, USA) with 10\% fetal bovine serum $(\mathrm{FBS})$, penicillin $(100 \mathrm{U} / \mathrm{ml})$ and streptomycin $(100 \mu \mathrm{g} / \mathrm{ml})$ at $37{ }^{\circ} \mathrm{C}$ under $5 \% \mathrm{CO}_{2}$. The effect of the recombinant MBP-CssPLA2 on the production of collagen I by LX-2 cells was assessed by ELISA. Cells were removed from the cell-culture plastic bottle by trypsin and seeded into 6-well culture plates $(6,000$ cells/well, Nest, Wuxi, China) in the presence of DMEM containing $10 \%$ FBS for $24 \mathrm{~h}$. Diluted in DMEM with $2 \%$ FBS, $25 \mu \mathrm{g} / \mathrm{ml}$ ESPs, $25 \mu \mathrm{g} / \mathrm{ml} \mathrm{MBP,} 25 \mu \mathrm{g} / \mathrm{ml} \mathrm{MBP-CssPLA2} \mathrm{and} \mathrm{PBS}$ were included with cells. After $36 \mathrm{~h}$ or $48 \mathrm{~h}$, the supernatant of cells was detected by ELISA. Collagen I rabbit antibody (1:2,000 dilutions, Abcam, London, UK) was used as the first antibody and HRP-conjugated goat antirabbit IgG was used as the secondary antibody $(1: 10,000$ dilutions, Proteintech, Chicago, USA). Each well was incubated with tetramethylbenzidine (TMB) solution. Finally, the reaction was stopped by $2 \mathrm{M} \mathrm{H}_{2} \mathrm{SO}_{4}$, and the absorbance of each well was detected at $450 \mathrm{~nm}$.

\section{Detection of a-SMA in LX-2 cells by Western blotting}

The effects of the recombinant MBP-CssPLA2 on LX-2 activation were assessed by Western blot. The expression of activation markers normalized by $\beta$-actin was detected in LX-2, which were divided into three groups and incubated with $25 \mu \mathrm{g} / \mathrm{ml} \mathrm{MBP,} 25 \mu \mathrm{g} / \mathrm{ml} \mathrm{MBP-}$ CssPLA2 and PBS, respectively, for $48 \mathrm{~h}$. To further investigate the dose dependence of MBP-CssPLA2 and the effect of the JNK inhibitor in the process, LX-2 cells were then divided into five groups and incubated with $25 \mu \mathrm{g} / \mathrm{ml}$ MBP, $10 \mu \mathrm{g} / \mathrm{ml}$ MBP-CssPLA2, $25 \mu \mathrm{g} / \mathrm{ml}$ MBP-CssPLA2, PBS and $25 \mu \mathrm{g} / \mathrm{ml}$ MBP-CssPLA2 together with $5 \mu \mathrm{M}$ JNK inhibitor (SP600125), respectively, for $48 \mathrm{~h}$. Then all the cells were lysed by cell lysing buffer and concentration of protein was detected by bicinchoninic acid (BCA) protein assay kit (Novagen, Darmstadt, Germany). The recombinant protein MBP-CssPLA2 was subjected to SDS-PAGE (12\% polyacrylamide gel) and immobilized onto a polyvinylidenedifluoride membrane. The membrane was incubated with the primary antibodies ( $\alpha$-SMA antibody, 1:500 dilutions in 1\% BSA-PBS) (Proteintech, Chicago, USA) overnight at $4{ }^{\circ} \mathrm{C}$ after blocking with $5 \%$ skim milk at room temperature for $2 \mathrm{~h}$. Then the membrane was washed and incubated with goat anti-rabbit immunoglobulin G conjugated HRP (1:5,000 dilution) (Proteintech, Chicago, USA) at room temperature for $1 \mathrm{~h}$. The results were visualized by chemiluminescence (chemiluminescent HRP substrate, Milipore, Billerica, USA). 
Quantitative RT-PCR analysis of activation markers of LX-2 LX-2 cells were incubated with $25 \mu \mathrm{g} / \mathrm{ml}$ MBP-CssPLA2, $25 \mu \mathrm{g} / \mathrm{ml}$ mutant and $25 \mu \mathrm{g} / \mathrm{ml}$ MBP-CssPLA2 together with $5 \mu \mathrm{M}$ JNK inhibitor (SP600125), respectively, for 24 h. Total RNA was extracted from LX-2 cells using Trizol. One microgram of total RNA was reverse transcribed into cDNA with the reverse transcriptase kit (Takara, Dalian, China). Using SYBR Premix ExTaq, cDNA was used as the template for PCR amplification. The primers of human smooth muscle actin ( $\alpha$-SMA) were $5^{\prime}$-CCA GGG CTG TTT TCC CAT CC-3' (forward primer) and 5'-GCT CTG TGC TTC GTC ACC CA-3' (reverse primer). The primers of human collagen III were 5'-GGT CCT CCT GGA ACT GCC GGA-3' (forward primer) and 5'-GAG GAC CTT GAG CAC CAG CGT GT-3' (reverse primer). The primers of human $\beta$-actin were $5^{\prime}$-GTC CAC CGC AAA TGC TTC TA-3' (forward primer) and 5'-T GC TCT CAC CTT CAC CGT TC-3' (reverse primer). The human $\beta$-actin served as the internal standard. PCR conditions were as follows: $95{ }^{\circ} \mathrm{C}$ for $30 \mathrm{~s}, 40 \mathrm{cy}-$ cles of $95{ }^{\circ} \mathrm{C}$ for $5 \mathrm{~s}$, and $60{ }^{\circ} \mathrm{C}$ for $20 \mathrm{~s}$, with an incremental increase of $0.1{ }^{\circ} \mathrm{C} / \mathrm{s}$ from 60 to $95{ }^{\circ} \mathrm{C}$.

\section{Detection of P-JNK1 in LX-2 cells incubated with MBP-} CssPLA2 and the mutant respectively by Western blotting The effects of the recombinant MBP-CssPLA2 and the mutant on JNK signalling activation in LX-2 cells was assessed by Western blot. LX-2 cells were incubated for $48 \mathrm{~h}$ with $25 \mu \mathrm{g} / \mathrm{ml}$ MBP, $25 \mu \mathrm{g} / \mathrm{ml}$ MBP-CssPLA2, $25 \mu \mathrm{g}$ / $\mathrm{ml}$ mutant and PBS, respectively. The expression of phospho-JNK1 was detected and normalized by $\beta$-actin in LX-2 cells. Then all the cells were lysed by cell lysing buffer and concentration of protein was detected by bicinchoninic acid (BCA) protein assay kit (Novagen). The protein was subjected to SDS-PAGE (12\% polyacrylamide gel) and immobilized onto a polyvinylidenedifluoride membrane. The membrane was incubated with the primary antibodies (P-JNK1 antibody, 1:1000 dilutions in 1\% BSA-PBS) (CST, Boston, USA) overnight at $4{ }^{\circ} \mathrm{C}$ after blocking with $5 \%$ skim milk at room temperature for $2 \mathrm{~h}$. Then the membrane was washed and incubated with goat anti-rabbit immunoglobulin G conjugated HRP (1:5000 dilution) (Proteintech, Chicago, USA) at room temperature for $1 \mathrm{~h}$. The results were visualized by chemiluminescence (chemiluminescent HRP substrate, Millipore, Billerica, USA)).

\section{Statistical analysis}

Results were analyzed by the software GraphPad Prism 5 using the method $t$-test to compare the difference between the experimental group and the control group, considering values of $P<0.05$ as significant.

\section{Results}

Prokaryotic expression and purification of MBP-CssPLA2 The length of PCR product of CssPLA2 was 828 bp (Fig. 1a). The soluble MBP-CssPLA2 was expressed with a MBP tag in E. coli BL21 (DE3) after being induced with $0.3 \mathrm{mM}$ IPTG at $37{ }^{\circ} \mathrm{C}$ for $4 \mathrm{~h}$. The recombinant protein was purified by amylose resin (Fig. 1b) and anion exchange chromatography (Fig. 1c). The purified MBP fusion protein showed a single band with a molecular mass around $76 \mathrm{kDa}$ in $12 \%$ SDS-PAGE, consistent with the predicted molecular mass (Fig. 1d). The protein MBP-CssPLA2 was identified by both western blot with the CssPLA2 monoclonal antibody (Fig. 2a) and mass spectrometry (Fig. 2b). The final protein concentration was $0.5 \mathrm{mg} / \mathrm{ml}$ while the concentration of endotoxinfree MBP-CsPLA2 was about $0.2 \mathrm{mg} / \mathrm{ml}$.

\section{Enzymatic activity of MBP-CssPLA2}

The enzymatic activity of MBP-CssPLA2 was detected with sPLA2 Assay Kit, it showed good enzymatic activity with protein MBP as a negative control and bee venom sPLA2 as a positive control (Fig. 3a). The enzyme was heat resistant and showed good enzymatic activity at $50{ }^{\circ} \mathrm{C}$ (Fig. 3b). The enzymatic activity got better with either higher concentration of enzyme or higher concentration of substrate until an optimum concentration was obtained. (Fig. 3c, d).

\section{Liver fibrosis and activation of the JNK signalling pathway} by MBP-CssPLA2 in liver tissue of $\mathrm{Balb} / \mathrm{C}$ mouse

Liver sections of five groups of $\mathrm{Balb} / \mathrm{C}$ mice with hematoxylin/eosin (HE) and Masson staining were observed under a microscope. Collagen was stained blue in liver sections with Masson staining. The group of mice given an abdominal injection of $50 \mu \mathrm{g}$ MBP-CssPLA2 showed obvious collagen accumulation compared with other groups (Fig. 4a). Western blot of the liver tissue of the five groups of mice was also done to detect whether JNK signalling pathway was activated. Consistent with the result of liver sections with Masson staining, the group of mice given an abdominal injection of $50 \mu \mathrm{g}$ MBP-CssPLA2 showed activation of JNK signalling pathway and a clear band of P-JNK1 can be observed (Fig. 4b). Relative quantitative western blot analysis of PJNK1 was performed to compare the difference between experimental group and control group (AlphaView Software was used to adjust the gray level of western blot image). Figure 4c provides an illustration of three independent experiments. Unpaired t-tests revealed significant differences between the group injected with $50 \mu \mathrm{g}$ MBP-CssPLA2 and the group injected with $100 \mu \mathrm{g} \operatorname{MBP}\left(t_{(4)}=3.298, P=0.03\right)$. 


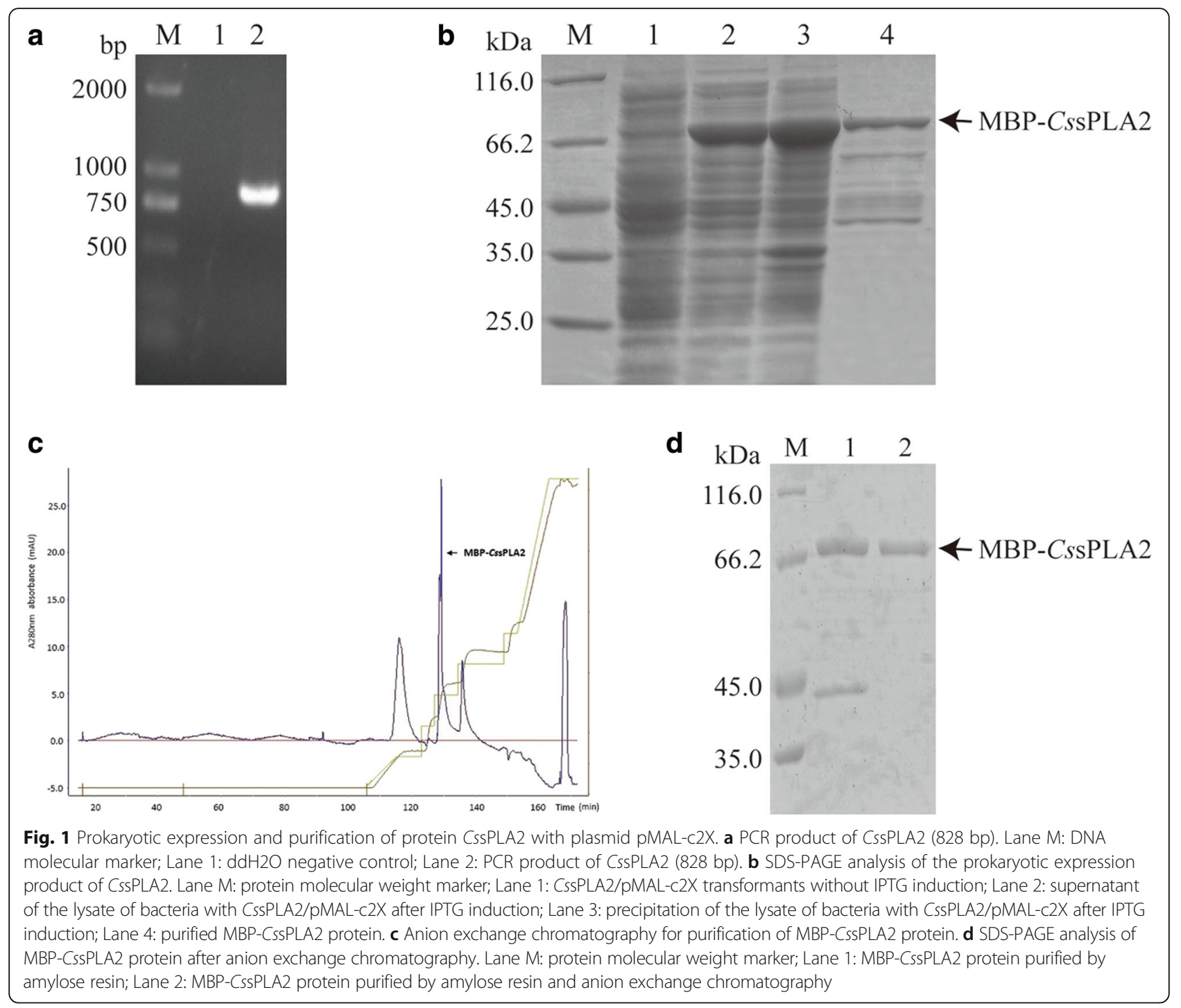

\section{Construction of MBP-CssPLA2 mutant}

PCR amplification with the plasmid CssPLA2/pMAL$\mathrm{c} 2 \mathrm{X}$ as a template was done to obtain the plasmid of the mutant (Fig. 5a). The mutant protein lost the enzymatic activity (Fig. 5b). The nucleotide sequences of the plasmid of the mutant were confirmed by DNA sequencing (Fig. 5c, d).

\section{JNK signalling pathway is involved in activation of LX-2 cells by MBP-CssPLA2}

The effect of MBP-CssPLA2 on activation of hepatic stellate cells and production of collagen I was evaluated by ELISA. Either after $36 \mathrm{~h}$ (Fig. 6a) or $48 \mathrm{~h}$ (Fig. 6b), the group of cells incubated with $25 \mu \mathrm{g} / \mathrm{ml}$ MBP-CssPLA2 showed the largest amount of collagen I in the supernatant of cell culture. Figure 6 provides an illustration of three independent experiments. Unpaired t-tests revealed significant differences between the group incubated with $25 \mu \mathrm{g} / \mathrm{ml} \mathrm{MBP-CssPLA2} \mathrm{and} \mathrm{the} \mathrm{group} \mathrm{incubated}$ with $25 \mu \mathrm{g} / \mathrm{ml} \mathrm{MBP}\left(t_{(4)}=5.02, P=0.0074\right.$ ) (Fig. 6a) and $\left(t_{(4)}=8.78, P=0.0009\right)$ (Fig. 6b).

Western blot was also done to detect the activation of hepatic stellate cells. The marker of the activation, $\alpha-$ SMA of the hepatic stellate cells, was measured after incubated with $25 \mu \mathrm{g} / \mathrm{ml} \mathrm{MBP,} 25 \mu \mathrm{g} / \mathrm{ml} \mathrm{MBP-CssPLA2}$ and PBS respectively. The hepatic stellate cells incubated with $25 \mu \mathrm{g} / \mathrm{ml}$ MBP-CssPLA2 showed a clear band of $\alpha$-SMA (Fig. 7a).

To detect whether the activation of hepatic stellate cells by MBP-CssPLA2 was dose-dependent and whether the activation was related to activation of JNK signalling pathway, two more groups, the group of cells incubated with $10 \mu \mathrm{g} / \mathrm{ml} \mathrm{MBP-CssPLA2}$ and the group of cells incubated with both $25 \mu \mathrm{g} / \mathrm{ml}$ MBP-CssPLA2 and $5 \mu \mathrm{M}$ JNK inhibitor (SP600125) were added. Western blot was done again and MBP-CssPLA2 showed a dose-dependent effect on 


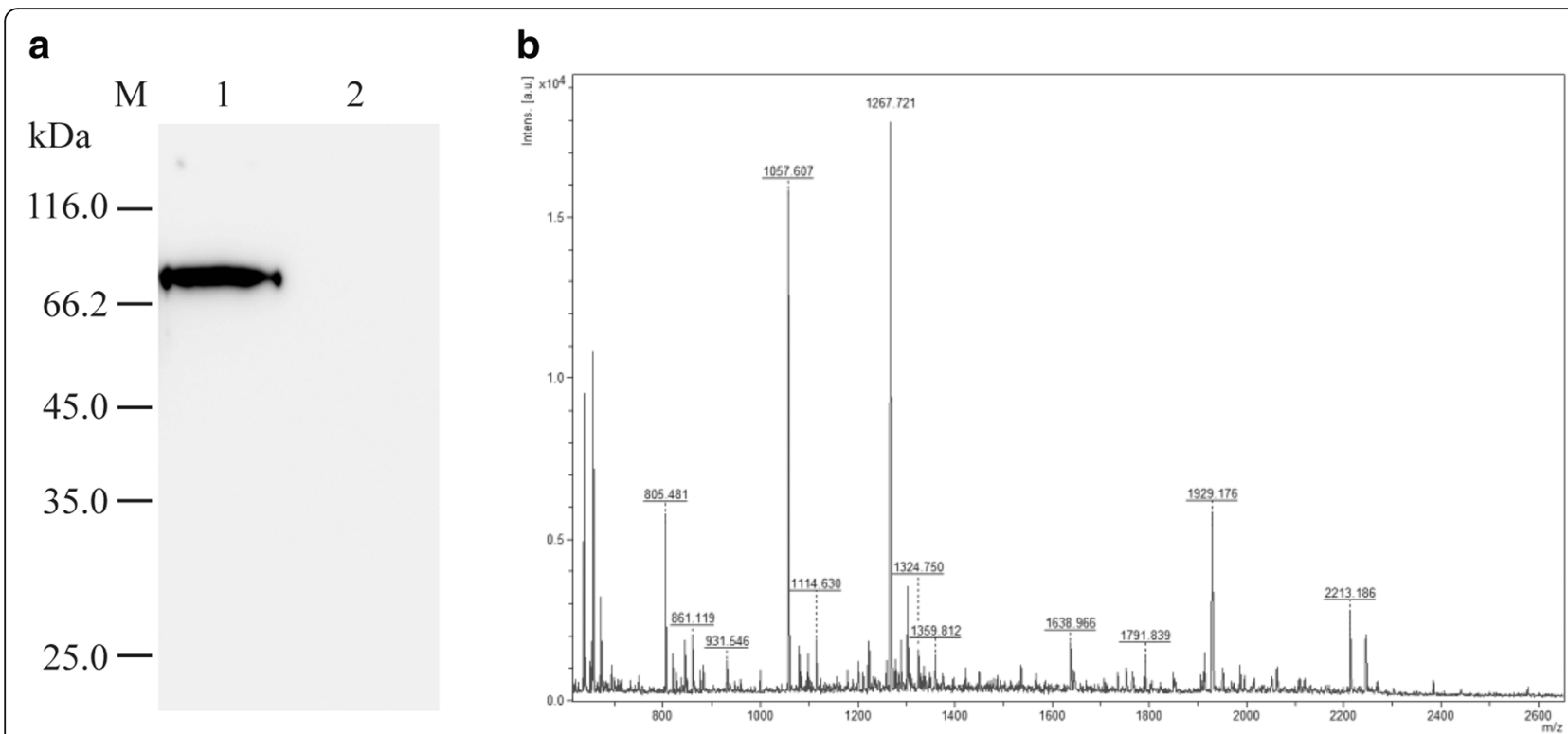

Fig. 2 Identification of protein MBP-CssPLA2 by western blot and mass spectrum. a The recombinant protein MBP-CsSPLA2 was identified by western blot with CsSPLA2 monoclonal antibody. CsSPLA2 monoclonal antibody (1:3,000 dilution) was used as first antibody and goat anti-mouse immunoglobulin G conjugated HRP (1:2000 dilution) was used as the second antibody. Lane 1: the recombinant protein MBP-CssPLA2; Lane 2: protein MBP. $\mathbf{b}$ The recombinant protein MBP-CsSPLA2 was identified by mass spectrometry
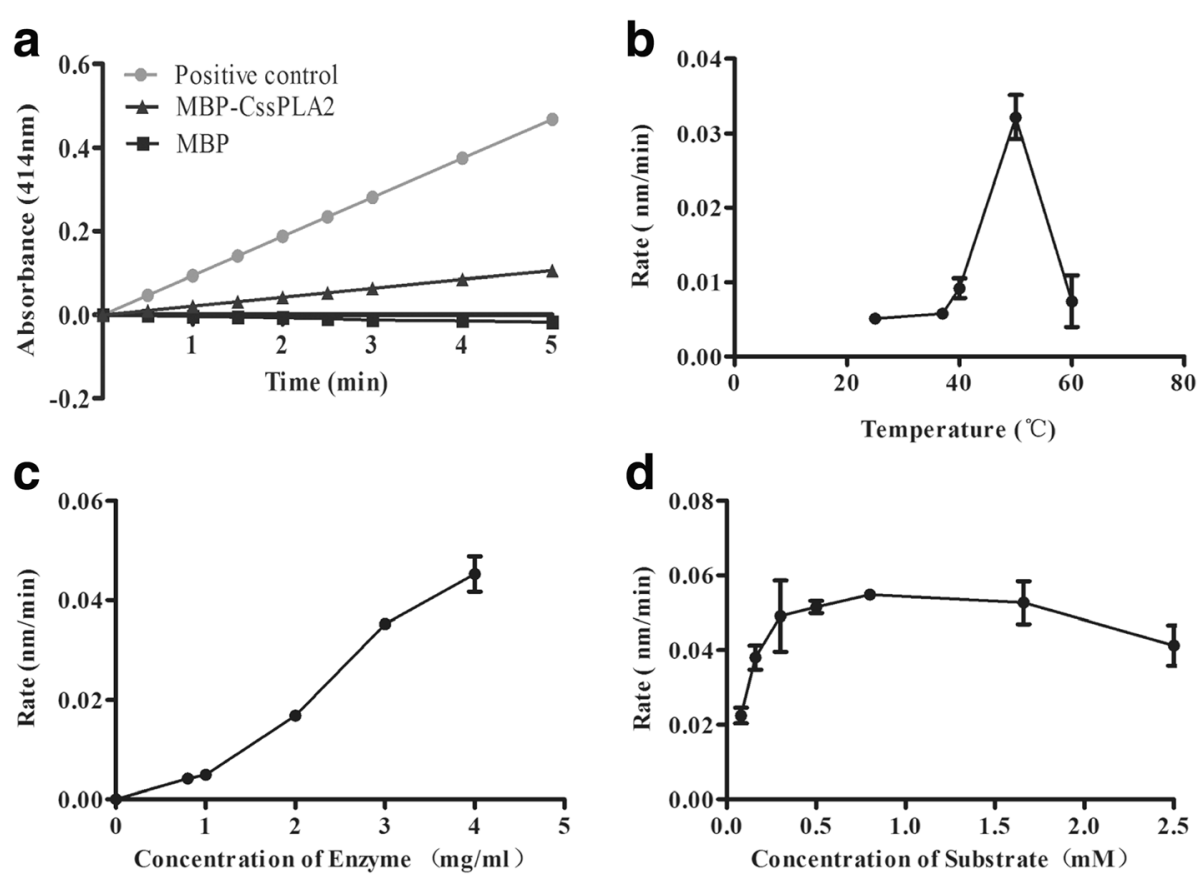

Fig. 3 Detection of the enzymatic activity of MBP-CSSPLA2. The enzyme activity of CssPLA2 was detected by sPLA2 Assay Kit. Bee venom PLA2 was used as positive controls and the MBP protein expressed by empty plasmid pMAL-c2X was used as negative control. a Detection of enzymatic activity of MBP-CSSPLA2. $\mathbf{b}$ Influence of the temperature on the enzymatic activity of MBP-CsSPLA2. $\mathbf{c}$ Influence of enzyme concentration to enzymatic activity of MBP-CssPLA2. $\mathbf{d}$ Influence of the substrate concentration on the enzymatic activity of MBP-CSSPLA2 

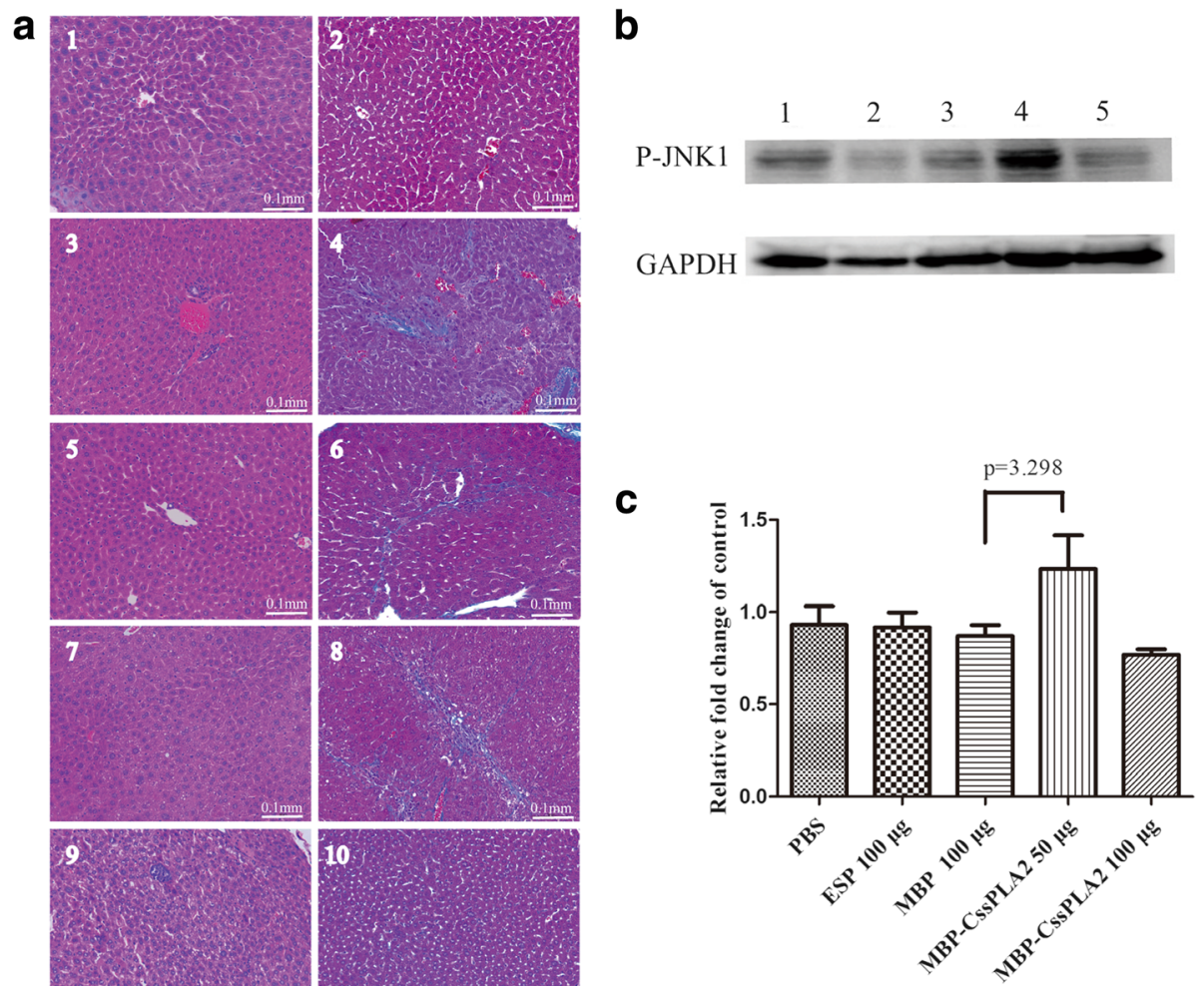

Fig. 4 JNK signalling was activated in the liver tissue of Balb/C mouse with abdominal injection of MBP-CssPLA2. a Liver sections of five groups of Balb/C mouse with HE and Masson staining. Sections 1 \& 2, HE and MASSON staining of liver sections of Balb/C mouse with an abdominal injection of PBS; Sections 3 \& 4, HE and MASSON staining of liver sections of Balb/C mouse with an abdominal injection of $100 \mu \mathrm{\mu g}$ ESPs; Sections 5 \& 6 , HE and MASSON staining of liver sections of Balb/C mouse with an abdominal injection of $100 \mu \mathrm{g} \mathrm{MBP;} \mathrm{Sections} 7 \&$ \&: HE and MASSON staining of liver sections of Balb/C mouse with an abdominal injection of $50 \mathrm{\mu g}$ MBP-CsSPLA2; Sections 9 \& 10, HE and MASSON staining of liver sections of Balb/C mouse with an abdominal injection of $100 \mu \mathrm{g}$ MBP-CsSPLA2; $\mathbf{b}$ Western blot of liver tissue of five groups of Balb/C mouse with P-JNK1 monoclonal antibody. Lane 1: Liver tissue of Balb/C mouse with an abdominal injection of PBS; Lane 2: Liver tissue of Balb/C mouse with an abdominal injection of $100 \mathrm{mg}$ ESPs; Lane 3: Liver tissue of Balb/C mouse with an abdominal injection of $100 \mu \mathrm{g} \mathrm{MBP;}$ Lane 4: Liver tissue of Balb/C mouse with an abdominal injection of $50 \mu \mathrm{g}$ MBP-CSSPLA2; Lane 5: Liver tissue of Balb/C mouse with an abdominal injection of $100 \mu \mathrm{g}$ MBP-CssPLA2. c Quantitative western blot analysis of P-JNK1. Unpaired $t$-test was applied for statistical analysis. Compared with control group, JNK signalling of experimental group, the liver tissue of Balb/C mouse with an abdominal injection of $50 \mu \mathrm{g}$ MBP-CSSPLA2 was activated $\left(t_{(4)}=3.298, P=0.03\right)$

activation of hepatic stellate cells as well as relation with activation of the JNK signalling pathway (Fig. 7b). Relative quantitative western blot analysis of $\alpha$-SMA was performed to compare the difference between experimental group and control group. Figure 7c provides an illustration of three independent experiments. Unpaired t-tests revealed significant differences between the group incubated with $25 \mu \mathrm{g} / \mathrm{ml} \mathrm{MBP-CssPLA2}$ and the group incubated with $25 \mu \mathrm{g} / \mathrm{ml}$ MBP $\left(t_{(2)}=23.63, \quad P=0.0018\right)$, between the group incubated with $25 \mu \mathrm{g} / \mathrm{ml} \mathrm{MBP-}$ CssPLA2 and the group incubated with $25 \mu \mathrm{g} / \mathrm{ml} \mathrm{MBP-}$ CssPLA2 + $5 \mu \mathrm{M}$ JNK inhibitor $\left(t_{(2)}=64.77, P=0.0002\right)$.

To determine whether the activation of hepatic stellate cells by MBP-CssPLA2 was related to the enzymatic activity of the protein or not, the hepatic stellate cells were divided into three groups and incubated with $25 \mu \mathrm{g} / \mathrm{ml}$ mutant, $25 \mu \mathrm{g} / \mathrm{ml} \mathrm{MBP-CssPLA2,} \mathrm{and} 25 \mu \mathrm{g} / \mathrm{ml} \mathrm{MBP-}$ CssPLA2 $+5 \mu \mathrm{M}$ JNK inhibitor (SP600125), respectively.
Quantitative RT-PCR analysis of activation markers of LX-2 was performed. The mRNA of $\alpha-S M A$ and collagen III were detected, and the difference between the group incubated with the mutant and the group incubated with MBP-CssPLA2 was of no statistical significance, while the difference between the group incubated with MBPCssPLA2 and the group incubated with both $25 \mu \mathrm{g} / \mathrm{ml}$ MBP-CssPLA2 and $5 \mu \mathrm{M}$ JNK inhibitor (SP600125) was significant: $t_{(4)}=3.905, P=0.0175$ (Fig. 8 a) and $t_{(4)}=4.095$, $P=0.0149$ (Fig. 8b). Unpaired $t$-test was applied and the difference between the group incubated with the mutant and the group incubated with MBP-CssPLA2 was of no statistical significance.

Western blot was done to detect the activation of JNK signalling in HSCs incubated with MBP-CssPLA2 and the mutant. The marker of activation, phospho-JNK1 of HSCs, was measured after incubated with $25 \mu \mathrm{g} / \mathrm{ml}$ MBP, $25 \mu \mathrm{g} / \mathrm{ml} \mathrm{MBP-CssPLA2,} 25 \mu \mathrm{g} / \mathrm{ml}$ mutant and 
a $\quad$ c

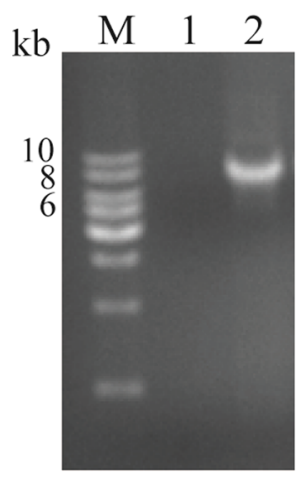

C

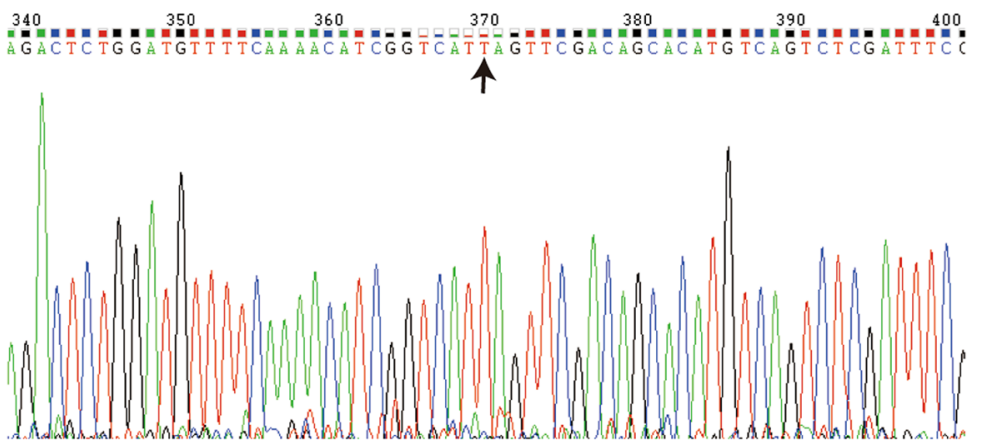

b

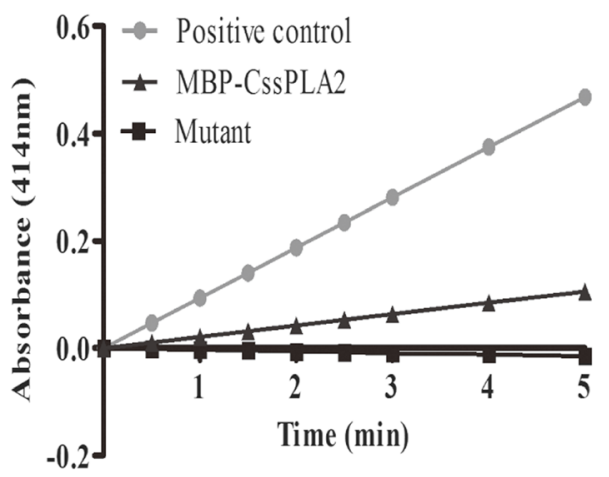

d

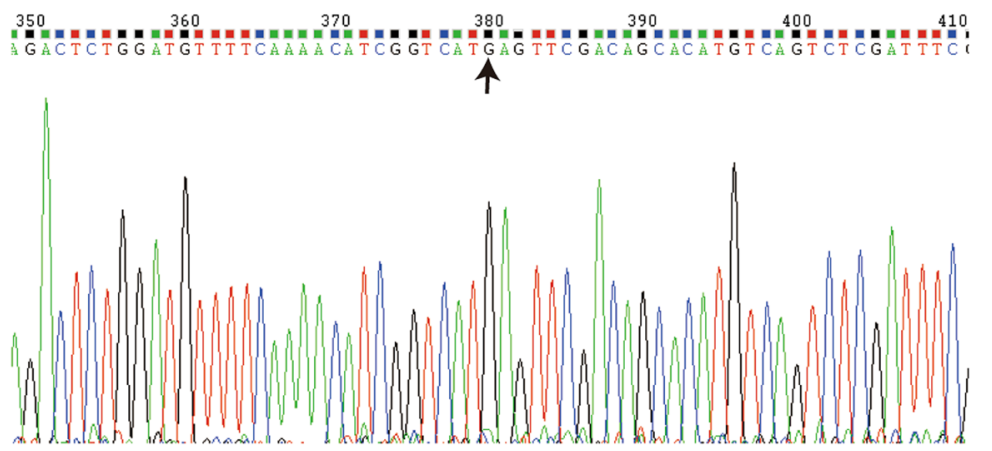

Fig. 5 Construction of mutant of MBP-CSSPLA2 without enzymatic activity. a PCR product of the plasmid of the mutant. Lane M: DNA molecular marker; Lane 1: ddH2O negative control; Lane 2: PCR product of mutant of MBP-CSSPLA2. b Detection of enzymatic activity of the mutant. $\mathbf{c}$ Sequence of the mutant plasmid of CssPLA2/pMAL-c2X. $\mathbf{d}$ Sequence of the plasmid of CssPLA2/pMAL-c2X
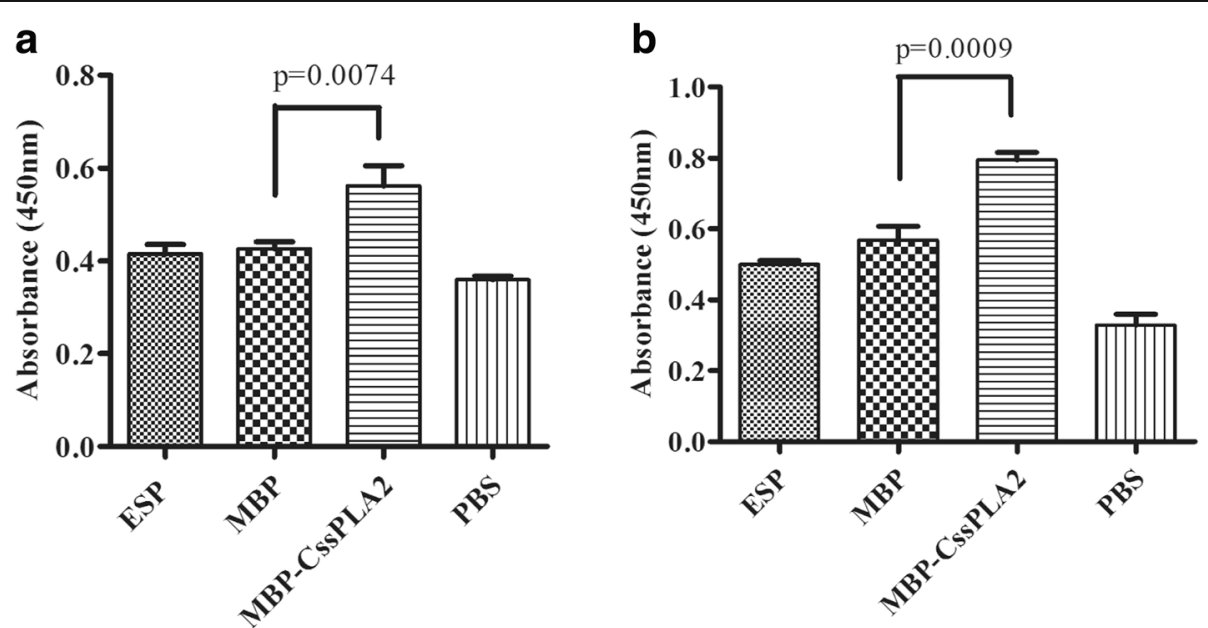

Fig. 6 Collagen I produced by HSCs are increased after incubated with MBP-CSSPLA2. The effect of MBP-CSSPLA2 on activation of hepatic stellate cells and production of collagen I was evaluated by ELISA. After $36 \mathrm{~h}$ or $48 \mathrm{~h}$, the supernatant of cells was detected by ELISA. Collagen I rabbit antibody (1:2000 dilutions) was used as the first antibody and HRP-conjugated goat anti-rabbit IgG was used as a secondary antibody (1:10,000 dilution). a Supernatant of cell culture after incubation for $36 \mathrm{~h}$; b supernatant of cell culture after incubation for $48 \mathrm{~h}$. Unpaired $t$-test was applied for statistical analysis 


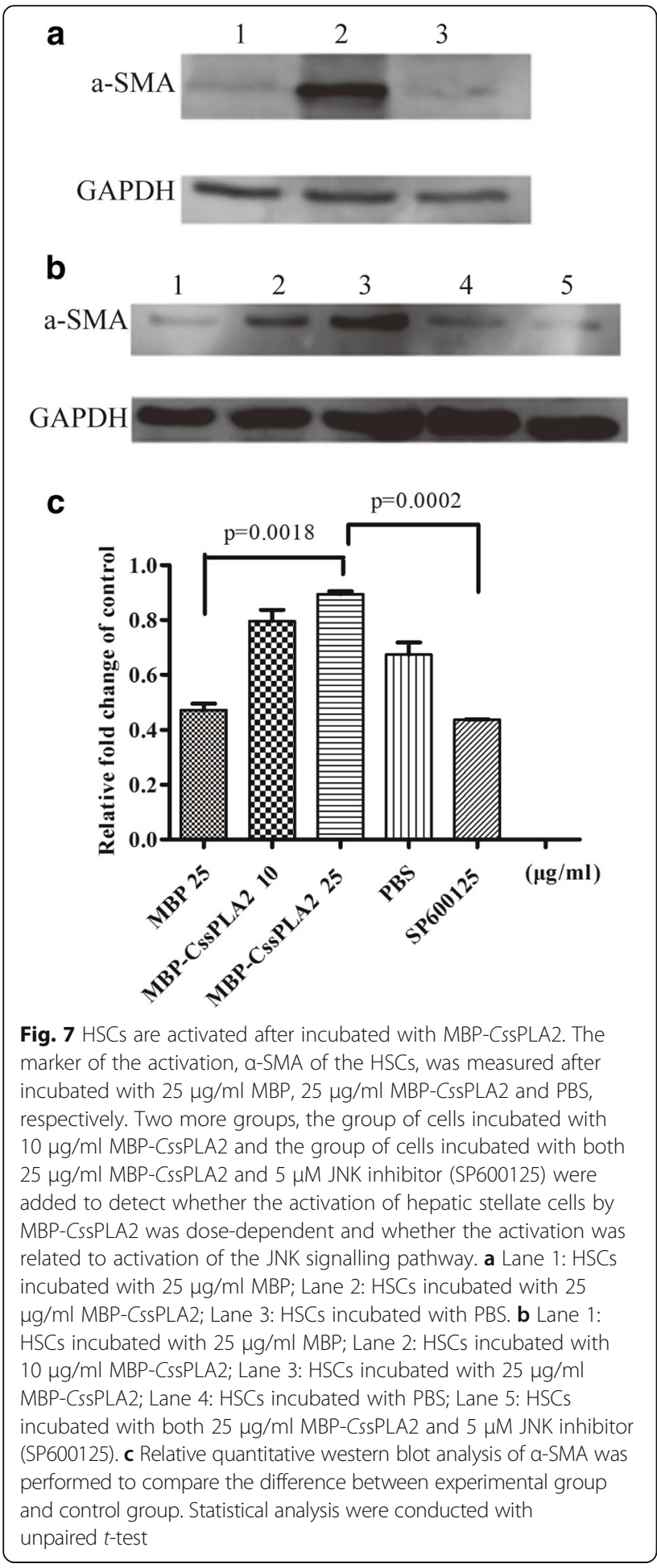

PBS, respectively. Both HSCs incubated with $25 \mu \mathrm{g} / \mathrm{ml}$ MBP-CssPLA2 and that incubated with $25 \mu \mathrm{g} / \mathrm{ml}$ mutant showed a clear band for P-JNK1 (Fig. 9a). Relative quantitative western blot analysis of P-JNK1 was performed to compare the difference between experimental group and control group. Figure $9 \mathrm{~b}$ provides an illustration of three independent experiments. Unpaired t-tests revealed significant differences between the group incubated with $25 \mu \mathrm{g} / \mathrm{ml} \mathrm{MBP-CssPLA2}$ and the group incubated with $25 \mu \mathrm{g} / \mathrm{ml} \mathrm{MBP}\left(t_{(4)}=4.899, P=0.008\right)$, between the group incubated with $25 \mu \mathrm{g} / \mathrm{ml}$ mutant and the group incubated with $25 \mu \mathrm{g} / \mathrm{ml} \mathrm{MBP}\left(t_{(4)}=3.605\right.$, $P=0.0227$ ).

\section{Discussion}

ESPs are continuously released by adult $C$. sinensis and contribute to interactions between the parasite and the host [19]. sPLA2 is a protein secreted by $C$. sinensis and is a component of CsESPs. After incubated with CsESPs for $24 \mathrm{~h}, \mathrm{LX}-2$ cells could be activated. It's proved that CsESPs play an important role in liver fibrosis caused by clonorchiasis. Cell proliferation was detected by methyl thiazolyltetrazolium (MTT) assay when LX-2 cells were incubated with $50 \mu \mathrm{g} / \mathrm{ml}$ of CsESPs [20]. The phospholipase A2 has been well known for its function in liver fibrosis and inhibition of tumor cells. It's suggested by the present findings that ASB14780, an IVA-PLA2 inhibitor, could be effective for the treatment of hepatic fibrosis [21]. PLA2 is an abundant component of snake venom. Bothropstoxin-I, a Lys49-phospholipase A2, which from Bothrops jararacussu venom was proved to cause cell death for both human and murine tumor cell lines by inducing apoptosis or necrosis [22]. In the present study, we have expressed the recombinant protein MBPCssPLA2, which is water-soluble with good enzymatic activity. Balb/C mice were given an abdominal injection of MBP-CssPLA2 to detect whether the protein could activate hepatic stellate cells in vivo, and cause accumulation of collagen which leads to liver fibrosis. Hepatic stellate cells were also incubated with the protein MBPCssPLA2 to detect the activation of the cells in vitro. It was proved that MBP-CssPLA2 could activate hepatic stellate cells and cause accumulation of collagen both in vivo and in vitro. This result was in accordance with the finding that the deficiency of mouse PLA2 could attenuate hepatic fibrosis formation [14]. The mutant without enzymatic activity was constructed to investigate the mechanism of activation of HSCs by MBP-CssPLA2, while it was found that activation of HSCs was not related to the enzymatic activity of the protein. To clarify whether JNK signalling pathway is involved and activated during the process, JNK inhibitor (SP600125) was applied. SP600125 is a broad spectrum JNK inhibitor for JNK1, JNK2 and JNK3 with IC50 of $40 \mathrm{nM}, 40 \mathrm{nM}$ and $90 \mathrm{nM}$, respectively; 10-fold greater selectivity against MKK4, 25-fold greater selectivity against MKK3, MKK6, PKB, and PKC $\alpha$, and 100fold selectivity against ERK2, p38, Chk1, GFR etc. In cell free assay, IC50 value is 40/40/90 nM (JNK1/2/3). However, in a cell based assay, the recommended concentration of SP600125 is 5-10 $\mu \mathrm{M}$. In Jurkat T cells, SP600125 

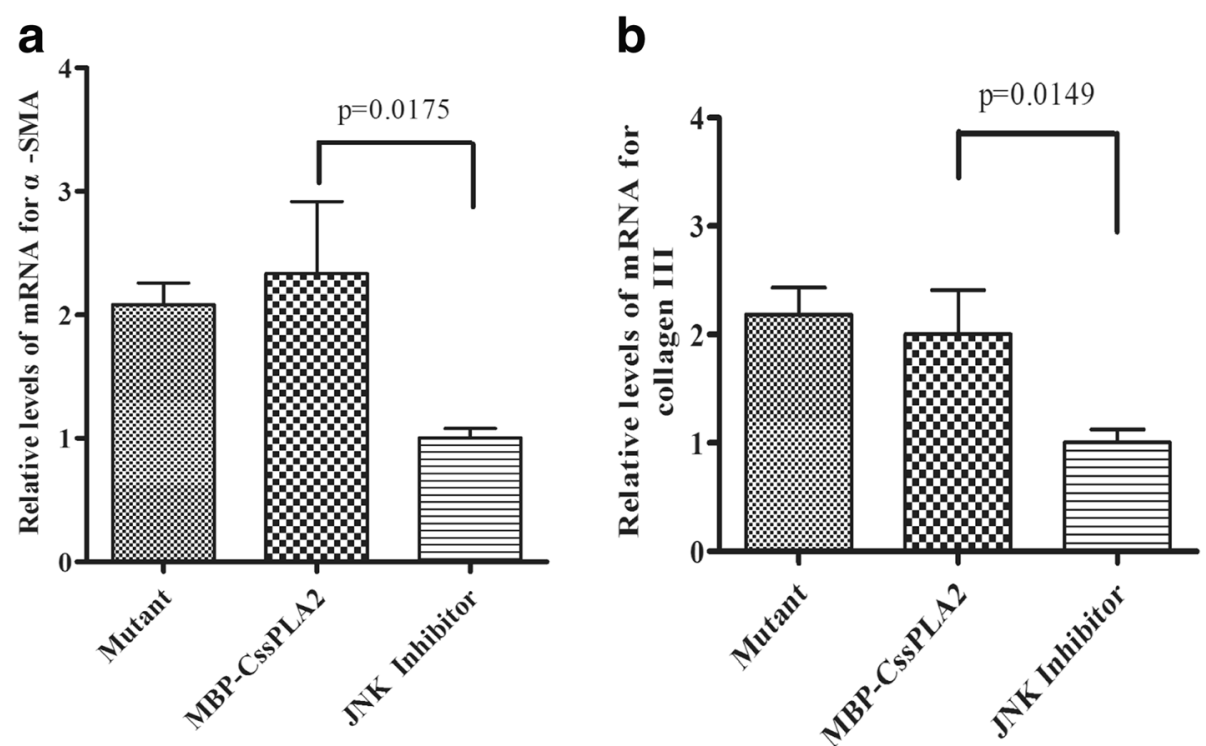

Fig. $8 \mathrm{HSCS}$ are activated after incubated with either MBP-CSSPLA2 or the mutant. Quantitative RT-PCR analysis of activation markers of LX-2 was performed. The mRNA of a-SMA and collagen III were detected, respectively. The transcription levels of a -SMA and collagen III were analyzed by means of the $2^{-\Delta \Delta C t}$ ratio, with human $\beta$-actin serving as the internal standard. The transcription level of a-SMA and collagen III in LX-2 cells incubated with $25 \mu \mathrm{g} / \mathrm{ml}$ mutant and $25 \mu \mathrm{g} / \mathrm{ml} \mathrm{MBP-CssPLA2}$ was similar, with no statistical significance, while that of LX-2 cells incubated with both $25 \mu \mathrm{g} / \mathrm{ml}$ MBP-CsSPLA2 and $5 \mu \mathrm{M}$ JNK inhibitor (SP600125) was lower than that of cells incubated with $25 \mu \mathrm{g} / \mathrm{ml} \mathrm{MBP-CssPLA2}$. Unpaired t-test was applied to compare the difference between experimental group and control group. a The relative levels of mRNA for a-SMA of three groups of $L X-2$ cells incubated with $25 \mu \mathrm{g} / \mathrm{ml}$ mutant, $25 \mu \mathrm{g} / \mathrm{ml}$ MBP-CssPLA2 and both $25 \mu \mathrm{g} / \mathrm{ml}$ MBP-CssPLA2 and $5 \mu \mathrm{M}$ JNK inhibitor (SP600125), respectively $\left(t_{(4)}=3.905\right.$, $P=0.0175)$. $\mathbf{b}$ Relative levels of mRNA for collagen III of three groups of LX-2 cells incubated with $25 \mu \mathrm{g} / \mathrm{ml}$ mutant, $25 \mu \mathrm{g} / \mathrm{ml}$ MBP-CSsPLA2 and both $25 \mu \mathrm{g} / \mathrm{ml}$ MBP-CssPLA2 and $5 \mu \mathrm{M}$ JNK inhibitor (SP600125), respectively $\left(t_{(4)}=4.095, P=0.0149\right.$ )

inhibits the phosphorylation of c-Jun with IC50 of $5 \mu \mathrm{M}$ to $10 \mu \mathrm{M}$ [23]. It was found that JNK signalling pathway activation had activated the hepatic stellate cells. Western blot showed that both MBP-CssPLA2 and the mutant could activate JNK signalling.

The spatial structure of CssPLA2 is complex. Therefore, it was difficult to express the protein in water-soluble form with enzymatic activity. The recombinant protein CssPLA2 was expressed by pET-28a vector as insoluble inclusion bodies and renatured by dilution and dialysis [12]. We also tried other prokaryotic vectors, such as pET-30a, pET-26b, pET-32a and pGEX-4T-1, but all the products were inclusion bodies, without enzymatic activity. Finally, the vector pMAL-c2X was chosen and water-soluble protein was expressed with good enzymatic activity. pMAL-c2X is a prokaryotic vector with a MBP (maltose binding protein) tag, which can promote the solubility of proteins. Either GST or TRX can be used for soluble expression of protein, while the MBP is much more effective $[24,25]$.

The sn-2 ester bond of phospholipids is hydrolysed by phospholipase A2 enzyme through a nucleophile water molecule and catalytic histidine. The histidine conformation is critical for PLA2 to hydrolyse the phospholipids [13]. The protein itself is an enzyme, and therefore, there are two ways for it to work. It works by its enzymatic activity or by activating the cell signalling pathway. The construction of a mutant was to identify which way the protein works. The mutant was the same as the protein MBP-CssPLA2 except for one amino acid difference. The 192nd amino acid of the mutant is asparagine instead of histidine, which is the most important amino acid related to the catalytic ability of the enzyme. The pathogenesis of liver fibrosis involves extracellular matrix protein deposition, including collagen I and collagen III, and requires activation of HSCs. JNK signalling pathway is related to HSCs activation. When JNK activity was blocked by the inhibitor SP600125, HSCs activity was inhibited, with reduced proliferation and less expression of $\alpha$-smooth muscle actin ( $\alpha$-SMA) [15].

Liver fibrosis, a worldwide medical problem characterised by excessive deposition of extracellular matrix (ECM) proteins, is a scarring process caused by chronic liver injury [26, 27]. The predominant hepatic cells in the liver tissue contributing to excessive ECM deposition are HSCs [28]. As a stable and an unlimited source of human HSCs, LX-2 cell line is widely used for studying human liver fibrosis [29]. When quiescent HSCs are stimulated by liver insults, the lipid droplets are lost and a new myofibroblastic phenotype is obtained, with 


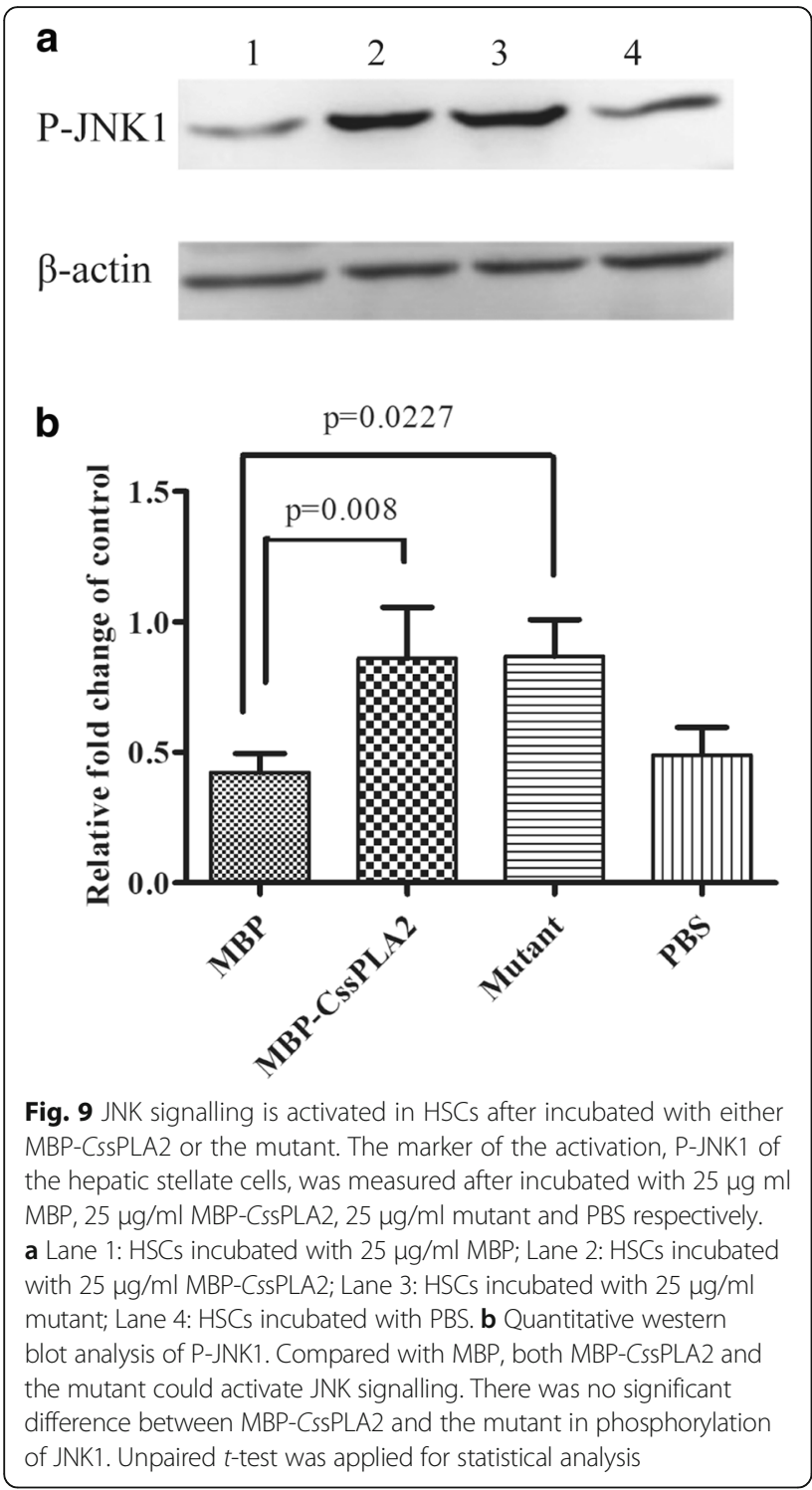

increased expression of ECM proteins and $\alpha$-SMA [30]. The LX-2 cells were activated by the recombinant protein MBP-CssPLA2 both in vitro and in vivo.

\section{Conclusions}

CssPLA2, as one component of CsESPs, can activate HSCs resulting in accumulation of collagen in vivo, which could be the reason of liver fibrosis and it can increase the level of a-SMA in hepatic stellate cells in a dose-dependent manner in vitro, which is the characteristic of activation of HSCs. The activation of hepatic stellate cells by CssPLA2 is related to activation of the JNK signalling pathway instead of the enzymatic activity of the protein, which could provide a promising strategy to interrupt the process of liver fibrosis caused by infection of Clonorchis sinensis.

\section{Abbreviations}

a-SMA: a-smooth muscle actin; CCA: Cholangiocarcinoma.; CsSPLA2: Secreted phospholipase A2 of Clonorchis sinensis; ECM: Extracellular matrix; ESPs: Excretory and secretory products; HSCs: Hepatic stellate cells; MBP: Maltose binding protein; sPLA2: Secreted phospholipase A2

\section{Acknowledgements}

We thank Ms. Xuanhong Zhang in instruments center, Zhongshan School of Medicine, Sun Yat-sen University for providing help in the procedure of anion exchange chromatography.

\section{Funding}

This work was supported by the National Natural Science Foundation of China (No. 81641094), the National Key Research and Development Program of China (Nos. 2016YFC1202003, 2016YFC1202005), the Guangdong Natural Science Foundation (No. S2012010008504), and the 111 Project (No. B12003) to XL. The National Key Basic Research and Development Project of China (973 project; No.2010CB530000), the Guangdong Natural Science Fund (No. S2012010008504), and National Natural Science Foundation of China (No. 81171602) to XY. Sun Yat-sen Creative Project (No. 201601089) to YJ.

\section{Availability of data and materials}

The nucleic acid sequence of CSSPLA2 supporting the conclusions of this article is available in the GenBank repository (Accession number: DQ 974199). The protein information of CSSPLA2 supporting the conclusions of this article are available in the GenBank repository (Accession number: ABL07371.1).

\section{Authors' contribution}

$Y W, X L$ and $X Y$ conceived and designed the experiments; $Y W, Y L, M S, Y J, C W$ and $L Z$ performed the experiments; $X L, Y W, X Y, Y J, A H, T C, Y H$ and $Z L$ analyzed the data; $A S A B$ reviewed and edited the manuscript for English clarity. YW and $\mathrm{XL}$ wrote the manuscript. All authors read and approved the final manuscript.

\section{Competing interests}

The authors declare that they have no competing interests.

\section{Consent for publication}

Not applicable.

\section{Ethics approval}

All animals were housed in accordance with guidelines from the Association for the Assessment and Accreditation of Laboratory Animal Care (AAALAC). All protocols for animals were approved by the Institutional Review Board and conducted in the Institutional Animal Care and Use Committee (IACUC) of Sun Yat-sen University (permit number SCXK Guangdong, 2009-2011).

\section{Publisher's Note}

Springer Nature remains neutral with regard to jurisdictional claims in published maps and institutional affiliations.

\section{Author details}

${ }^{1}$ Department of Parasitology, Zhongshan School of Medicine, Sun Yat-sen University, Guangzhou, Guangdong 510080, People's Republic of China. ${ }^{2}$ Key Laboratory of Tropical Disease Control (Sun Yat-sen University), Chinese Ministry of Education, Guangzhou, Guangdong 510080, People's Republic of China. ${ }^{3}$ Provincial Engineering Technology Research Center for Biological Vector Control, Guangzhou, Guangdong 510080, People's Republic of China.

Received: 27 October 2016 Accepted: 7 March 2017

Published online: 16 March 2017

\section{References}

1. Furst T, Keiser J, Utzinger J. Global burden of human food-borne trematodiasis: a systematic review and meta-analysis. Lancet Infect Dis. 2012;12(3):210-21.

2. Qian MB, Chen YD, Liang S, Yang GJ, Zhou XN. The global epidemiology of clonorchiasis and its relation with cholangiocarcinoma. Infect Dis Poverty. 2012;1(1):4.

3. Qian MB, Chen YD, Yan F. Time to tackle clonorchiasis in China. Infect Dis Poverty. 2013;2:1-4. 
4. $\quad$ Qian MB, Utzinger J, Keiser J, Zhou XN. Clonorchiasis. Lancet. 2016; 387(10020):800-10.

5. Wei DX, Yang WY, Huang SQ, Lu YF, Su TC, Ma JH, et al. Parasitological investigation on the ancient corpse of the Western Han Dynasty unearthed from tomb No. 168 on Phoenix Hill in Jiangling county. Acta Acad Med Wuhan. 1981;1(2):16-23.

6. Li S, Chung YB, Chung BS, Choi MH, Yu JR, Hong ST. The involvement of the cysteine proteases of Clonorchis sinensis metacercariae in excystment. Parasitol Res. 2004;93(1):36-40.

7. Choi D, Lim JH, Lee KT, Lee JK, Choi SH, Heo JS, et al. Gallstones and Clonorchis sinensis infection: A hospital-based case-control study in Korea. J Gastroen Hepatol. 2008;23(8pt2):e399-404.

8. Qiao T, Ma RH, Luo ZL, Yang LQ, Luo XB, Zheng PM. Clonorcis sinensis eggs are associated with calcium carbonate gallbladder stones. Acta Trop. 2014; 138:28-37.

9. Qiao T, Ma RH, Luo XB, Luo ZL, Zheng PM. Cholecystolithiasis is associated with Clonorchis sinensis infection. PLoS ONE. 2012;7(8):e42471.

10. Sripa B, Kaewkes S, Intapan PM, Maleewong W, Brindley PJ. Chapter 11 Food-borne trematodiases in Southeast Asia: Epidemiology, pathology, clinical manifestation and control. Adv Parasitol. 2010;72:305-350.

11. Murakami M, Sato H, Miki Y, Yamamoto K, Taketomi Y. A new era of secreted phospholipase A2. J Lipid Res. 2015;56(7):1248-61.

12. Hu F, Hu X, Ma C, Zhao J, Xu J, Yu X. Molecular characterization of a novel Clonorchis sinensis secretory phospholipase A2 and investigation of its potential contribution to hepatic fibrosis. Mol Biochem Parasitol. 2009;167(2):127-34.

13. Hariprasad G, Kota D, Baskar Singh S, Srinivasan A, Adhikary S. Delineation of the structural elements of oriental liver fluke PLA2 isoforms for potent drug designing. Indian J Clin Biochem. 2014;29(4):430-41.

14. Ishihara K, Miyazaki A, Nabe T, Fushimi H, Iriyama N, Kanai S, et al. Group IVA phospholipase A2 participates in the progression of hepatic fibrosis. FASEB J. 2012;26(10):4111-21.

15. Schnabl B, Bradham CA, Bennett BL, Manning AM, Stefanovic B, Brenner DA TAK1/JNK and p38 have opposite effects on rat hepatic stellate cells. Hepatology. 2001;34(5):953-63.

16. Soares AM, Guerra-Sá R, Borja-Oliveira CR, Rodrigues VM, Rodrigues-Simioni $\mathrm{L}$, Rodrigues V, et al. Structural and functional characterization of BnSP-7, a Lys49 myotoxic phospholipase A2 homologue from bothrops neuwiedi pauloensis venom. Arch Biochem Biophys. 2000;378(2):201-9.

17. Cavalcante WLG, Silva MD-P, Gallacci M. Influence of temperature upon paralyzing and myotoxic effects of bothropstoxin-I on mouse neuromuscular preparations. Chem Biol Interact. 2005;151(2):95-100

18. Araya C, Lomonte B. Antitumor effects of cationic synthetic peptides derived from Lys49 phospholipase A2 homologues of snake venoms. Cell Biol Int. 2007:31(3):263-8.

19. Ren M, He L, Huang Y, Mao Q, Li S, Qu H, et al. Molecular characterization of Clonorchis sinensis secretory myoglobin: delineating its role in anti-oxidative survival. Parasit Vectors. 2014;7:250.

20. Wang X, Hu F, Hu X, Chen W, Huang Y, Yu X. Proteomic identification of potential Clonorchis sinensis excretory/secretory products capable of binding and activating human hepatic stellate cells. Parasitol Res. 2014;113(8):3063-71.

21. Kanai S, Ishihara K, Kawashita E, Tomoo T, Nagahira K, Hayashi Y, et al. ASB14780, an orally active inhibitor of group IVA phospholipase A2, is a pharmacotherapeutic candidate for nonalcoholic fatty liver disease. J Pharmacol Exp Ther. 2016;356(3):604-14.

22. Prinholato da Silva C, Costa TR, Paiva RMA, Cintra ACO, Menaldo DL Antunes LMG, et al. Antitumor potential of the myotoxin BthTX-I from Bothrops jararacussu snake venom: evaluation of cell cycle alterations and death mechanisms induced in tumor cell lines. J Venom Toxins. 2015; 21(1):1-8.

23. Bennett BL, Sasaki DT, Murray BW, O'Leary EC, Sakata ST, Xu W, et al. SP600125, an anthrapyrazolone inhibitor of Jun N-terminal kinase. Proc Natl Acad Sci USA. 2001;98(24):13681-6.

24. Goh LL, Loke $P$, Singh $M$, Sim TS. Soluble expression of a functionally active Plasmodium falciparum falcipain-2 fused to maltose-binding protein in Escherichia coli. Protein Expr Purif. 2003;32(2):194-201.

25. Kapust RB, Waugh DS. Escherichia coli maltose-binding protein is uncommonly effective at promoting the solubility of polypeptides to which it is fused. Protein Sci. 1999:8(8):1668-74

26. Bataller R, Brenner DA. Liver fibrosis. J Clin Invest. 2005;115(2):209-18.

27. Karsdal MA, Manon-Jensen T, Genovese F, Kristensen JH, Nielsen MJ, Sand $J M$, et al. Novel insights into the function and dynamics of extracellular matrix in liver fibrosis. Am J Physiol Gastrointest Liver Physiol. 2015;308(10): G807-30.

28. Yin C, Evason KJ, Asahina K, Stainier DY. Hepatic stellate cells in liver development, regeneration, and cancer. J Clin Invest. 2013;123(5):1902-10.

29. Herrmann J, Gressner AM, Weiskirchen R. Immortal hepatic stellate cell lines: useful tools to study hepatic stellate cell biology and function? J Cell Mol Med. 2007;11(4):704-22.

30. Mallat A, Lotersztajn S. Cellular mechanisms of tissue fibrosis. 5. Novel insights into liver fibrosis. Am J Physiol Cell Physiol. 2013;305(8):C789-99.

\section{Submit your next manuscript to BioMed Central and we will help you at every step:}

- We accept pre-submission inquiries

- Our selector tool helps you to find the most relevant journal

- We provide round the clock customer support

- Convenient online submission

- Thorough peer review

- Inclusion in PubMed and all major indexing services

- Maximum visibility for your research

Submit your manuscript at www.biomedcentral.com/submit
) Biomed Central 